American Journal of Pharmaceutical Education 2019; 83 (5) Article 7410.

\title{
COMMENTARY
}

\section{The Need for Palliative Care in Pharmacy Education}

\author{
Jennifer Pruskowski, PharmD, ${ }^{a}$ Ravi Patel, PharmD, ${ }^{a}$ Gayle Brazeau, $\mathrm{PhD}^{\mathrm{b}, \mathrm{c}}$ \\ ${ }^{a}$ University of Pittsburgh School of Pharmacy, Pittsburgh, Pennsylvania \\ ${ }^{\mathrm{b}}$ Marshall University, Huntington, West Virginia \\ ${ }^{c}$ Editor, American Journal of Pharmaceutical Education, Arlington, Virginia
}

Submitted October 16, 2018; accepted February 28, 2019; published June 2019.

\begin{abstract}
There is a growing need for palliative care pharmacists in the United States. There is also a gap in the education of palliative care for pharmacy students. To address both, pharmacy schools must develop and disseminate palliative care-focused experiences, including traditional didactic lectures, problembased learning, interactive skills, laboratory- and web-based experiences. This commentary presents the need for palliative care-focused experiences in the Doctor of Pharmacy (PharmD) degree program, and how schools can take smaller steps to tackle this issue.
\end{abstract}

Keywords: palliative care, education, pharmacy, pain, pharmacists

"I don't understand. Isn't there something you can do to help? He can't even interact with us and he looks like he's suffering. There has to be a medication for this, right?"

Caring for an 83-year-old African American male suffering from terminal delirium second to Alzheimer's dementia and his family may be a rare experience for a pharmacist but the themes this vignette presents are not. Every day pharmacists are faced with difficult cases where today's binary world of evidence-based literature, organizational guidelines and multiple-choice examinations fall short of the knowledge, skills and attitudes needed to navigate the gray areas of pharmacy. To add, every day pharmacists prioritize a patient's quality over quantity of life. Every day, maybe even without recognizing it, pharmacists are palliative care providers.

According to the World Health Organization, palliative care is an approach that improves the quality of life of patients and their families facing problems associated with serious illness, through the prevention and relief of suffering by means of early identification and impeccable assessment and treatment of pain and other problems, physical, psychosocial and spiritual. ${ }^{1}$ A serious illness requires continuing treatment by health care providers and includes conditions such as cancer, dementia, congestive heart failure and chronic obstructive pulmonary disease. Palliative care is often given in conjunction with curative therapies. The ratio of palliative versus curative therapies depends on the patient's functional status, prog-

Corresponding Author: Jennifer Pruskowski, 3600 Forbes Ave. at Meyran Ave., Ste. 308.15, Pittsburgh, PA 15229. Tel: 412-864-2899. Email: pruskowskija@upmc.edu nosis and care goals. The palliative care approach has been referred to as "the three C's": comfort, communication and coordination. ${ }^{2}$ Palliative care providers are experts in the management of pain and other symptoms. As patients with serious illness often face challenging decisions, palliative care providers are trained to conduct high-quality discussions about a patient's goals. Understanding these goals allows all providers to align and improve care coordination. Coordination is particularly important if a patient decides to elect the Medicare Part A hospice benefit.

Hospice care, a subset of palliative care, is for people who are terminally ill and have opted for a comfort treatment plan. ${ }^{3}$ Terminally ill is defined as a prognosis of six months or less. Hospice services are provided to patients by nongovernmental agencies and are regulated by Medicare Part A. Through the hospice benefit, patients receive access to a hospice physician, nurse, social worker, and chaplain; medical equipment and supplies; short-term respite care; access to an inpatient facility for aggressive pain and symptom management; and prescription medications related to the hospice diagnosis. ${ }^{4}$ These services are provided at a low or no out-of-pocket cost to the patient. To supplement costs, Medicare provides the hospice agency a per patient, per diem rate.

Pharmacists play a crucial role in the specialty of palliative care. ${ }^{5}$ In clinical practice, palliative care providers will work within hospice care agencies, or upstream within palliative care service lines in health care systems (hospitals, clinics, nursing homes, or home-care groups). ${ }^{6}$ Guidelines regarding the role of palliative care pharmacists have been published through the American Society of Health-System Pharmacy (ASHP). Essential, 


\section{American Journal of Pharmaceutical Education 2019; 83 (5) Article 7410.}

clinical and administrative roles are listed in Table $1 .{ }^{7}$ Palliative care clinical pharmacists can improve patient outcomes through the rational use of medications within each of "the three C's." First, comfort can be improved as medications remain the cornerstone of symptom management. Second, as patient-specific goals are established, a palliative care clinical pharmacist can extrapolate and make changes to the patient's medication regimen to reflect. Specifically, a palliative care clinical pharmacist can deprescribe potentially inappropriate or unnecessary medications. ${ }^{8}$ Deprescribing can also help ease a patient's transition to hospice care. Hospice agencies usually operate under specific formularies to optimize drug spending. A palliative care clinical pharmacist can improve coordination by considering the clinical utility of a medication and whether it would be covered by the hospice formulary. Palliative care clinical pharmacists also can lead formulary decisions or participate in medication preparation and dispensing.

There is a growing need for palliative care clinical pharmacists in the United States (US). A 2014 Center to Advance Palliative Care (CAPC) report found only 56 of 389 (14\%) inpatient palliative care programs included a pharmacist. ${ }^{9}$ As the population continues to grow, this gap will only widen. The US Administration on Aging predicts that by 2030 there will be more than 72.1 million Americans over 65 years of age, and CAPC predicts at least 6 million of those could benefit from palliative care. ${ }^{10,11}$ Palliative care has been shown to improve patient outcomes and increase value to health care systems. In a landmark 2010 clinical trial, patients with newly diagnosed metastatic non-small-cell lung cancer randomized to receive early palliative care integrated with standard oncologic care, over standard oncologic care alone, had a better quality of life, less depressive symptoms, and most importantly, longer survival despite less aggressive care. ${ }^{12}$ Less aggressive care included the reduction of potentially inappropriate or unnecessary medications.

There are many reasons for this growing need in clinical practice. First, hospice regulations specify the hospice team must include doctors, nurses, social workers and chaplains. The team can also include volunteers and therapists such as physical or music. Pharmacists are not required. Moreover, in many states, pharmacists cannot bill third party payers for services. Pharmacists practicing in palliative care are often not revenue generating sources for health care systems. Nevertheless, it is possible through the implementation of collaborative practice agreements that pharmacists can reduce physician and advance practice provider burden and time, and further improve outcomes. ${ }^{13}$

There is also a gap in the pharmacy curricula. A 2013 survey-based study found $82 \%$ of pharmacy schools $(\mathrm{N}=61$ respondents, $49 \%$ response rate) reported offering palliative care or end-of-life education. ${ }^{14}$ This was a small increase from a 2003 study with a similar design. ${ }^{15}$ Both studies noted only an average of 6 hours of curriculum time devoted to this material. When considering the total hours of didactic and experiential learning for a typical student pharmacist (approximately 400 hours), this accounts for less than $1 \%$ of the total curriculum time. Unfortunately, postgraduate opportunities are also limited. As of December 2018, there are only 25 pain and palliative care postgraduate year two (PGY2) programs, and a few traineeships and online programs available for pharmacists in the US. ${ }^{6,16}$

In 2012, the Pain and Palliative Care Strategic Planning Summit published recommendations to improve the education of palliative care for pharmacists and student pharmacists. Within the PharmD program, six 50-minute lecture equivalents are recommended (Table 2). ${ }^{17}$ Most of

Table 1. Essential Clinical and Administrative Roles of Palliative Care Pharmacists ${ }^{7}$

\begin{tabular}{ll}
\hline Direct Patient Care & $\begin{array}{c}\text { Optimize the outcomes of symptom management and palliative care patients through the expert } \\
\text { provision of evidence-based, patient-centered medication therapy as an integral part of an } \\
\text { interdisciplinary team } \\
\text { Serve as an authoritative resource on the optimal use of medications in symptom management } \\
\text { and palliative care } \\
\text { Anticipate transitions of care when recommending, initiating, modifying, or discontinuing } \\
\text { pharmacotherapy for pain and symptom }\end{array}$ \\
$\begin{array}{l}\text { Manage and improve the medication-use process in patient care settings } \\
\text { and Reconciliation }\end{array}$ \\
$\begin{array}{c}\text { Education and Medication } \\
\text { Counseling }\end{array}$ \\
$\begin{array}{c}\text { Demonstrate excellence in the provision of medication counseling to patients, caregivers, } \\
\text { administrative Roles }\end{array}$ \\
Ensure safe use of medications in the treatment of pain and symptoms \\
Medication supply chain management
\end{tabular}




\section{American Journal of Pharmaceutical Education 2019; 83 (5) Article 7410.}

Table 2. Consensus Recommendations for Time Commitment and Content for Pain and Palliative Care Instruction Within Required Coursework in Pharmacy Professional Degree Programs. (Part of the Recommendations from the Strategic Planning Summit for Pain and Palliative Care Pharmacy Practice) ${ }^{17}$

Content and Time Allocation (Minutes)

Example Competency Statements

\author{
Six 50-Minute Lecture Equivalents (300 Minutes) \\ Introduction and Overview (10 minutes) \\ Definition of Pain and Palliative Care (10 minutes) \\ Physiological Issues (0 minutes) (previously covered in earlier coursework) \\ Pain and Symptom Assessment and Management (15 minutes) \\ Pharmacologic Issues (0 minutes) (previously covered in earlier coursework) \\ Nonpharmacological Approaches to Pain (5 minutes) \\ Management of Common Pain Etiologies (180 minutes) \\ Management of Common Non-Pain Symptoms (20 minutes) \\ Analgesic Dosing Strategies (30 minutes) \\ Pharmaceutical Concerns (10 minutes) \\ Ethical/Legal Issues (20 minutes) \\ 2. Definition of Pain and Definition of Palliative Care (10 minutes) \\ 2.1. International Association for the Study of Pain nomenclature \\ 2.2. International Association for Hospice and Palliative Care nomenclature \\ 2.3. Systems for classifying pain \\ 2.3.1. Relationships and difference between acute pain and chronic pain \\ 2.4. Biologic significance of pain and survival value \\ 2.5. Concept of total pain (ie, physical, psychological, spiritual, and financial) \\ 4. Pain and Symptom Assessment and Management (15 minutes) \\ 4.1. Measurement, quantification, and recording of pain and symptoms \\ 4.2. Assessment of pain \\ 4.2.1. Symptom analysis \\ 4.2.2. Unidimensional and multidimensional tools \\ 4.2.3. Pain diaries \\ 4.3. Screening tools for risk of or current drug abuse and diversion \\ 4.3.1. Opioid Risk Tool \\ 4.3.2. Screener and Opioid Assessment for Patients with Pain \\ 4.3.3. Current Opioid Misuse Measure \\ 4.3.4. Diagnosis, Intractability, Risk, and Efficacy Score
}

these lectures focus on the management of pain and other symptoms. Since the Summit, the role of the palliative care pharmacist continues to evolve. There is now special recognition for the emotional, ethical, and economic costs of inadequate or overly aggressive care of those with serious illness. Palliative care clinical pharmacists are now developing and implementing pharmacist-driven deprescribing and transitions of hospice care programs. ${ }^{18}$

To address the growing need in clinical practice and gaps in the pharmacy curricula, pharmacy schools must develop and disseminate palliative care-focused experiences. Pharmacy schools can select from a variety of pathways, and Introductory Pharmacy Practice Experiences and Advanced Pharmacy Practice Experiences, and/or Areas of Concentrations or certificate programs can be valuable for those looking to specialize in palliative care after graduation. ${ }^{19}$

Even if student pharmacists do not choose to specialize in palliative care, the knowledge, skills and attitudes developed through palliative care-focused experiences can be applied to many fields of pharmacy practice. Pain is one of the most common reasons a patient accesses the health care system. ${ }^{20}$ Pharmacists equipped to manage pain and other symptoms are necessary for today's climate. Additionally, deprescribing is necessary for all populations. It has been estimated that drug-related morbidity and mortality in the US costs over $\$ 200$ billion annually. ${ }^{21}$ Potentially inappropriate or unnecessary medications likely contribute to this; these medications have been associated with an increased risk of adverse drug events, drug interactions, medication non-adherence and reduced functional capacity. ${ }^{22}$ Evidence has also suggested these experiences improve attitudes toward end of life and have been shown to decrease burnout. ${ }^{23,24}$ This is especially important as a 2015 survey-based study of pharmacy residency program directors noted pharmacy residents could be better prepared for the emotional challenges of patient care. $^{25}$ 


\section{American Journal of Pharmaceutical Education 2019; 83 (5) Article 7410.}

Palliative care-focused experiences highlight and focus on skills of empathy, critical thinking and communication. Empathy is necessary to establish a level of trust between the patient, family and pharmacist. Health care provider empathy increases patient satisfaction and may even lead to better health outcomes. Despite this, empathy in clinical encounters is often lacking and research suggests empathy in health science students decreases as they progress through graduate training. ${ }^{26,27}$ Critical thinking has been identified as a chief outcome of pharmacy school education. Student pharmacists upon graduation must be able to examine issues rationally, logically, and coherently as much of professional practice is problem-solving. Unfortunately, a 2009 prospective study conducted at a pharmacy school in North Carolina found no differences in critical thinking over one academic year. ${ }^{28}$ Interpersonal communication skills are also important for student pharmacists to master. Literature suggests regrettably that student pharmacists may not recognize their verbal communication deficiencies and therefore focused experiences are needed to teach these skills. ${ }^{29,30}$

The vignette presented at the beginning of this commentary will be revisited to defend the importance of these skills. Empathy is vital to strengthen the relationship between the pharmacist and family of the 83-year-old African American male suffering from terminal delirium second to Alzheimer's dementia. Critical thinking is necessary to determine the role of antipsychotics, and to identify possible deliriogenic-contributing or deprescribing-eligible medications. ${ }^{31}$ Critical thinking is also needed when conducting a nonverbal symptom assessment, especially when considering if inadequately treated symptoms are contributing to the delirium. ${ }^{32}$ Communication is essential when distinguishing care goals and aligning care coordination.

Incorporating palliative care-focused experiences into the PharmD curricula for the benefit of student training also benefits pharmacy schools. These experiences will improve a school's ability to meet the Accreditation Council for Pharmacy Education (ACPE) Standards. ${ }^{33}$ Appendix B of the 2011 Standards acknowledges the importance of palliative care and principles of end-of-life care as clinical science curricular content suggestions. ${ }^{34}$ In addition to improving skills of empathy, critical thinking and communication, palliative care-focused experiences notably bridge the gap between basic science and pharmacy practice. For example, pain management requires knowledge of pathophysiology, hypothesized mechanism(s) of action, as well as the pharmacokinetic and pharmacodynamic properties of medications. ${ }^{35}$ Though unlike the management of high blood pressure, an unbiased symptom assessment and medical chemistry extrapolation in lieu of evidence-based guidelines is necessary to determine the most rational medication regimen.

Incorporating these experiences will also elevate the PharmD curricula to equal its health science colleagues. In fact, the 2012 Summit was held partially in response to the then efforts to improve the education of physicians, nurses and social workers. A raw and limited December 2018 Pubmed literature search found almost 900 peer-reviewed articles involving the education of physicians, over 400 articles involving the education of nurses (search criteria: ("Palliative Care"[MeSH]) AND "Education, Medical/Nursing"[MeSH]), and close to 50 articles involving the education of social workers (search criteria: ("Palliative Care"[MeSH]) AND "Social Work"[MeSH]) AND "Education"[MeSH]). Only 21 articles were found regarding the education of pharmacists (search criteria: ("Palliative Care"[MeSH]) AND "Education, Pharmacy"[MeSH]). Currently three design themes have been used for palliative care-focused experiences within health science schools (Table 3): traditional didactic courses; interactive skill laboratory or end-of-life simulations; and web-based experiences. Various assessment methods have also been considered, including knowledge assessments or grading rubrics, reflective journaling or interviews, and surveys exploring attitudes and competencies with end-of-life experiences. Most experiences have been created for specific disciplines, while some have been interprofessional. ${ }^{35-47}$

Schools looking for small steps to incorporate palliative care-focused experiences into the PharmD curricula may look to Table 3 for reference. Many of these learning designs and assessment methods are already used by schools (eg, patient simulations), therefore finding places within the curriculum to adapt, or combine with, may be feasible and achievable. As palliative care is often given in conjunction with curative therapies, schools may not need to remove specific lectures or concepts to make room for these experiences. Also, any pharmacy practice faculty member can lead or drive these experiences. Broad concepts of palliative care are present in all other specialties, therefore even those faculty members who do not identify as palliative care clinicians can direct or participate.

An ideal palliative care-focused experience should include a novel approach of interactive skill laboratories or end-of-life simulations, plus web-based experiences. The Summit recommendations advocate for research and innovation in teaching methods and curricular design, including case study developments and pedagogical models which encourage interprofessional learning. ACPE Standard 10 discusses the need for student pharmacists to develop problem solving and critical thinking skills and 


\section{American Journal of Pharmaceutical Education 2019; 83 (5) Article 7410.}

Table 3. Design Themes Published Palliative Care-Focused Experiences within Health Science Schools

\begin{tabular}{ll}
\hline Author, Date & Publication \\
\hline Schools of Pharmacy & \\
Herndon C, $2010^{36}$ & Design: The Pain and Palliative Care Pharmacotherapy elective is a 2-credit hour course that meets for 16 \\
& weeks during the fall semester. A culminating experience required students to be "on-call," to test their \\
pharmacotherapy or monitoring decisions. \\
Assessment: A 100-point grading rubric was used to assess student pharmacists on timeliness of response, \\
professionalism, explanation of formulation of response and appropriateness of response. \\
Conclusion: This real-world practice experience was found to build both the students' confidence and their \\
ability to deal with pain management information requests when they enter practice. \\
Design: Thirty pharmacy students participated in a high-fidelity simulation 15 minutes before and 15 \\
minutes after the death of a patient with end-stage renal disease. \\
Assessment: Students completed the Attitudes Toward Death Survey and the End of Life Competency \\
Survey prior to and after experiencing the simulation. A reflections journal exercise was used to capture \\
post-simulation subjective reactions, and a course evaluation was used to assess students' satisfaction \\
with the simulation experience. \\
Conclusion: High-fidelity simulation is an innovative way to challenge pharmacy students' attitudes and \\
help them with knowledge acquisition about end-of-life care. \\
Design: A 3-week elective course in pain and palliative care was developed by integrating relevant \\
clinical and pharmaceutical sciences. Instructional strategies included lectures, team and individual \\
activities, case studies, and student presentations. \\
Assessment: Students who participated in the course in 2010 and 2011 were surveyed anonymously to \\
gain their perception about the class as well as the utility of the course during their Advance Pharmacy \\
Practice Experience (APPE) and in their everyday practice. \\
Conclusion: Students taking the integrated course on pain management and palliative care achieved \\
mastery of the learning outcome objectives.
\end{tabular}

\section{Schools of Medicine}

Day F, $2015^{38}$

Sittikariyakul P, $2015^{39}$
Design: All third-year medical students were enrolled into a quasi-randomized controlled trial of webbased interactive education (eDoctoring) compared with small-group education (Doctoring) on palliative and end-of-life (PEOL) clinical content over two months.

Assessment: Outcomes included a 24-item PEOL-specific self-efficacy scale with three domains: diagnosis/treatment, communication/prognosis, and social impact/self-care.

Conclusion: Findings showed equivalent gains in self-efficacy and knowledge between students participating in a web-based PEOL curriculum in comparison with students learning similar content in a smallgroup format.

Design: Nineteen family medicine residents were recruited as standardized patients (FMR-SPs) for a mandatory palliative care workshop in communication for incoming, first-year trainees.

Assessment: Four months later, FMR-SPs reflected upon their own experiences. Two independent researchers performed thematic analysis of these interviews.

Conclusion: Portraying SPs in palliative care appears to be a valuable learning experience for the resident.

Bergman J, 2016 ${ }^{40}$ Design: Participants took pre-test evaluations of attitudes and knowledge regarding end-of-life care prior to accessing the educational module, and a post-test evaluation following the module intervention.

Assessment: Study authors recorded the type of hyperlinks (guideline or paper) accessed by learners, and stratified participants into groups based on link type accessed (none, either, or both). Demographic and educational data to develop a multivariate mixed-effects regression analysis to develop adjusted predictions of attitudes and knowledge.

Conclusion: Auxiliary resources accessible by hyperlink are an effective adjunct to web-based learning in end-of-life care. 


\section{American Journal of Pharmaceutical Education 2019; 83 (5) Article 7410.}

Table 3. (Continued)

\begin{tabular}{ll}
\hline Author, Date & Publication \\
\hline $\begin{array}{l}\text { Schools of Nursing } \\
2013^{41}\end{array}$ & Design: A three-station palliative care Observed Structured Clinical Examination (OSCE) for Advance \\
& Practice Nurse (APN) students and physician fellows. Three stations included discussing goals of care, \\
breaking bad news, and assessing delirium. & \\
& Assessment: Measures included the Interpersonal Skills Tool, Station Checklists, the OSCE Evaluation \\
& Tool, and a focus group to solicit learners' perspectives about the experience. \\
& Conclusion: Initial evaluation suggests a three-station palliative care OSCE exercise is effective for \\
& multidisciplinary learners, although additional refinement is necessary. \\
Design: End of life simulation. & \\
Assessment: Attitudes toward caring for dying patients were measured pre- and post-simulation on a \\
convenience sample of 57 sophomore nursing students using the Frommelt Attitudes Toward Care of the \\
Dying Scale-Form B. \\
Conclusion: Simulation is an active learning strategy to incorporate end-of-life care in nursing curricula \\
and improve student attitudes toward caring for dying patients. \\
Design: Senior nursing students who completed End-of-Life Nursing Education Consortium (ELNEC) \\
core course. \\
Assessment: Descriptive pre- and post-assessment. \\
Conclusion: The ELNEC core course is an effective way to improve nursing students' knowledge of \\
palliative and end-of-life care.
\end{tabular}

\section{Schools of Social Work \\ Pulsford D, 2013 ${ }^{44}$}

Design: Systematic review of classroom-based and distance learning education and training initiatives for health and social care staff in end-of-life and palliative care.

Results: Thirty studies met eligibility criteria. The majority reported successful outcomes, though there were some exceptions.

Conclusion: Classroom-based education and training is useful for enhancing professionals' skills and perceived preparedness for delivering end-of-life care but should be reinforced by actual practice experience.

\section{Interprofessional Experiences}

Ellman MS, 2012 45

Saylor J, $2016^{46}$

Supiano KP, $2016^{47}$
Design: An educational program for students in medicine, nursing, chaplaincy, and social work. The program blended two sequential components: an online interactive, case-based learning module, and a live, dynamic simulation workshop.

Assessment: Content analysis was used to analyze students' free-text responses to four reflections in the online case, as well as open-ended questions on students' postworkshop questionnaires, which were also analyzed quantitatively.

Conclusion: Despite the challenge of balanced professional representation, this innovative interprofessional educational program met its learning objectives, and may be transferable for use in other educational settings.

Design: Based on experience level, teams of participants, 1 consisting of nursing/medical students and the other of nursing/medical health care professionals, completed a palliative care simulation as part of their education.

Assessment: Self-efficacy and attitudes toward physician-nurse collaboration were measured before and after simulation. Interprofessional competency was measured during the simulation.

Conclusion: The results revealed a significant improvement in the previously mentioned measures, and interprofessional competency scores varied by profession and evaluator.

Design: A graduate level course in palliative care for students in nursing, pharmacy, social work, and gerontology taught by faculty from each discipline. The overarching goals of this course are to convey core palliative care knowledge across disciplines, articulate the essential contribution of each discipline in collaborative care, and to define interdisciplinary processes learners need to understand and navigate interdisciplinary palliative care.

Assessment: Learning outcomes included increased knowledge, enhanced attitudes, increased ability to contribute discipline-specific knowledge to their teams' discussions, and confidence to participate in the care of these patients.

Conclusion: This graduate-level course met learning outcomes. 


\section{American Journal of Pharmaceutical Education 2019; 83 (5) Article 7410.}

encourages the use of active learning methods with the goal to develop self-directed, lifelong learners. Laboratories or simulations are best to develop and evaluate skills of critical thinking and communication. To maximize curriculum time and the school's resources, web-based experiences may help scale and disseminate other didactic learning objectives to student pharmacists or to include other disciplines. Technology already plays a central role in pharmacy and palliative care education, as well as our culture. ${ }^{48,49}$ Web-based experiences may help develop and evaluate a student pharmacist's empathy through the presentation of case-based studies.

Every day pharmacists are palliative care providers, even if they do not identify as one. However, the specialty of palliative care puts a spotlight on the skills necessary to place quality over quantity of life. Incorporating palliative care- focused experiences within the PharmD program will not only help pharmacy schools better meet ACPE Standards but provide skills to all student pharmacists that transcend every specialty and patient population. Novel approaches can be used and are encouraged to adapt current experiences or combine with others within the curriculum.

\section{ACKNOWLEDGMENTS}

The authors would like to acknowledge Maria Felton, PharmD, Michelle Howerton, PharmD, Emily Bobrzynski, PharmD, Lindsay Jablonski, PharmD, and Barbara Grden, PharmD, for their assistance with the content of this manuscript.

\section{REFERENCES}

1. WHO Definition of Palliative Care: World Health Organization. http://www.who.int/cancer/palliative/definition/en/. Accessed October 7, 2018.

2. Pruskowski J, Arnold R, Skledar SJ. Development of a healthsystem palliative care clinical pharmacist. Am J Health Syst Pharm. 2017;74(1):e6-e8.

3. Batchelor NH. Palliative or hospice care? Understanding the similarities and differences. Rehabil Nurs. 2010;35(2):60-64.

4. Medicare Hospice Benefits. Centers for Medicare \& Medicaid Services. https://www.medicare.gov/Pubs/pdf/02154-MedicareHospice-Benefits.PDF. Accessed October 7, 2018.

5. National Consensus Project for Quality Palliative Care. Clinical Practice Guidelines for Quality Palliative Care, 4th edition. Richmond, VA: National Coalition for Hospice and Palliative Care. https://www.nationalcoalitionhpc.org/ncp. Accessed January 2, 2019.

6. Pruskowski J. The role of clinical pharmacists on the interdisciplinary team \#334. J Palliat Med. 2017;20(8):897-899. 7. Herndon CM, Nee D, Atayee RS, et al. ASHP guidelines on the pharmacist's role in palliative and hospice care. Am J Health Syst Pharm. 2016;73(17):1351-1367.

8. Pruskowski J. Deprescribing \#321. J Palliat Med. 2017;20(2): 197-198.
9. National Palliative Care Registry. Center to Advance Palliative Care. https://registry.capc.org/. Accessed October 7, 2018. 10. A Profile of Older Americans: 2010. Administration on Aging, United States Department of Health and Human Services. https:// www.acl.gov/sites/default/files/Aging\%20and\%20Disability\%20in\% 20America/2010profile.pdf. Accessed October 7, 2018.

11. Palliative Care Facts and Stats. Center to Advance Palliative Care. https://media.capc.org/filer_public/68/bc/68bc93c7-14ad4741-9830-8691729618d0/capc_press-kit.pdf. Accessed October 7, 2018.

12. Temel JS, Greer JA, Muzikansky A, et al. Early palliative care for patients with metastatic non-small-cell lung cancer. $N$ Engl J Med. 2010;363(8):733-742.

13. Atayee RS, Sam AM, Edmonds KP. Patterns of palliative care pharmacist interventions and outcomes as part of inpatient palliative care consult service. J Palliat Med. 2018;21(12):1761-1767.

14. Dickinson GE. End-of-life and palliative care education in US pharmacy schools. Am J Hosp Palliat Care. 2013;30(6):532-535.

15. Herndon CM, Jackson K 2nd, Fike DS, Woods T. End-of-life care education in United States pharmacy schools. Am J Hosp Palliat Care. 2003;20(5):340-344.

16. Online Residency Directory. American Society of HealthSystem Pharmacists. https://accred.ashp.org/aps/pages/directory/ residencyprogramsearch.aspx. Accessed October 7, 2018.

17. Herndon CM, Strassels SA, Strickland JM, et al. Consensus recommendations from the strategic planning summit for pain and palliative care pharmacy practice. J Pain Symptom Manage. 2012; 43(5):925-44.e1-10.

18. Pruskowski J, Handler SM. The de-pharm project: a pharmacistdriven deprescribing initiative in a nursing facility. Consult Pharm. 2017;32(8):468-478.

19. Personalize Your PharmD Education: Geriatric and Palliative Care Area of Concentration. University of Pittsburgh School of Pharmacy. http://www.pharmacy.pitt.edu/programs/pharmd/ personalize.php. Accessed January 2, 2019.

20. St Sauver JL, Warner DO, Yawn BP, Jacobson DJ, et al. Why patients visit their doctors: assessing the most prevalent conditions in a defined American population. Mayo Clin Proc. 2013;88(1):56-67. 21. Isetts BJ, Brummel AR, de Oliveira DR, Moen DW. Managing drug-related morbidity and mortality in the patient-centered medical home. Med Care. 2012;50(11):997-1001.

22. Maher RL, Hanlon J, Hajjar ER. Clinical consequences of polypharmacy in elderly. Expert Opin Drug Saf. 2014;13(1):57-65. 23. Beall JW, Broseker AE. Pharmacy students' attitudes toward death and end-of-life care. Am J Pharm Educ. 2010;74(6):Article 104. 24. Chuang $\mathrm{CH}$, Tseng PC, Lin CY, et al. Burnout in the intensive care unit professionals: a systematic review. Medicine (Baltimore). 2016;95(50):e5629.

25. Pileggi DJ, Fugit A, Romanelli F, et al. Pharmacy residents' preparedness for the emotional challenges of patient care. Am J Health Syst Pharm. 2015;72(17):1475-1480.

26. Fjortoft N, Van Winkle LJ, Hojat M. Measuring empathy in pharmacy students. Am J Pharm Educ. 2011;75(6):Article 109. 27. Batt-Rawden SA, Chisolm MS, Anton B, Flickinger TE. Teaching empathy to medical students: an updated, systematic review. Acad Med. 2013 Aug;88(8):1171-1177.

28. Cisneros RM. Assessment of critical thinking in pharmacy students. Am J Pharm Educ. 2009;73(4):Article 66.

29. Luiz Adrian JA, Zeszotarski P, Ma C. Developing pharmacy student communication skills through role-playing and active learning. Am J Pharm Educ. 2015;79(3):Article 44. 


\section{American Journal of Pharmaceutical Education 2019; 83 (5) Article 7410.}

30. Parkhurst C. Assessing and improving students' verbal communication abilities in pharmacy courses. Am J Pharm Educ. 1994;58:50-55.

31. Atypical Antipsychotic Drugs Information. U.S. Food and Drug Administration. Accessed January 2, 2019. https://www.fda.gov/ Drugs/DrugSafety/ucm094303.htm

32. Warden V, Hurley AC, Volicer L. Development and psychometric evaluation of the Pain Assessment in Advanced Dementia (PAINAD) scale. J Am Med Dir Assoc. 2003;4(1):9-15. 33. Accreditation Council for Pharmacy Education (ACPE) Accreditation Standard and Guidelines for the Professional Program in Pharmacy Leading to the Doctor of Pharmacy Degree. https:// www.acpe-accredit.org/pdf/Standards2016FINAL.pdf. Accessed October 7, 2018.

34. Accreditation Council for Pharmacy Education (ACPE) Accreditation Standard and Guidelines for the Professional Program in Pharmacy Leading to the Doctor of Pharmacy Degree. https:// www.acpe-accredit.org/pdf/FinalS2007Guidelines2.0.pdf. Accessed January 2, 2019.

35. Kullgren J, Radhakrishnan R, Unni E, Hanson E. An integrated course in pain management and palliative care bridging the basic sciences and pharmacy practice. Am J Pharm Educ. 2013;77(6): Article 121.

36. Herndon CM, Lynch JC. A mock "on-call" experience for pharmacy students in a pain and palliative care elective. J Pain Palliat Care Pharmacother. 2010;24(4):387-392.

37. Gilliland I, Frei BL, McNeill J, Stovall J. Use of high-fidelity simulation to teach end-of-life care to pharmacy students in an interdisciplinary course. Am J Pharm Educ. 2012;76(4):Article 66. 38. Day FC, Srinivasan M, Der-Martirosian C, et al. A comparison of web-based and small-group palliative and end-of-life care curricula: a quasi-randomized controlled study at one institution. Acad Med. 2015;90(3):331-337.

39. Sittikariyakul P, Jaturapatporn D, Kirshen AJ. Acting as

standardized patients enhances family medicine residents' self-reported skills in palliative care. Adv Health Sci Educ Theory Pract. 2015;20(3): 645-654.

40. Bergman J, Ballon-Landa E, Lerman SE, et al. Engaging physician learners through a web-based platform: individualized end-of-life education. Am J Hosp Palliat Care. 2016;33(8):748754.

41. Corcoran AM, Lysaght S, Lamarra D, Ersek M. Pilot test of a three-station palliative care observed structured clinical examination for multidisciplinary trainees. J Nurs Educ. 2013;52(5):294-298.

42. Dame L, Hoebeke R. Effects of a simulation exercise on nursing students' end-of-life care attitudes. J Nurs Educ. 2016;55(12): 701-705.

43. Glover TL, Garvan C, Nealis RM, et al. Improving end-of-life care knowledge among senior baccalaureate nursing students. Am J Hosp Palliat Care. 2017;34(10):938-945.

44. Pulsford D, Jackson G, O'Brien T, et al. Classroom-based and distance learning education and training courses in end-of-life care for health and social care staff: a systematic review. Palliat Med. 2013;27(3):221-235.

45. Ellman MS, Schulman-Green D, Blatt L, et al. Using online learning and interactive simulation to teach spiritual and cultural aspects of palliative care to interprofessional students. $J$ Palliat Med. 2012;15(11):1240-1247.

46. Saylor J, Vernoony S, Selekman J, Cowperthwait A.

Interprofessional education using a palliative care simulation. Nurse Educ. 2016;41(3):125-129.

47. Supiano KP. Weaving interdisciplinary and discipline-specific content into palliative care education: one successful model for teaching end-of-life care. Omega (Westport). 2013;67(1-2):201206.

48. Smith MA, Benedict N. Effectiveness of educational technology to improve patient care in pharmacy curricula. Am J Pharm Educ. 2015;79(1):Article 15.

49. Weissman DE. Technology and the future of palliative care education. J Palliat Med. 2016;19(1):2-3. 